\title{
ANALISIS FAKTOR-FAKTOR YANG MEMPENGARUHI NIAT BELI KONSUMEN PRODUK MAKANAN DAN MINUMAN "HALAL" DI KOTA BATAM
}

Edy Yulianto Putra ${ }^{1 *}$, Yockie ${ }^{2}$

${ }^{1,2}$ Program Sarjana Manajemen, Universitas Internasional Batam, Indonesia

\author{
Article's Information \\ DOI: \\ http://dx.doi.org/10.37253/jgbmr \\ . $\mathrm{v} 2 \mathrm{i} 1$ \\ e-ISSN: \\ 2685-3426 \\ EDITORIAL HISTORY: \\ SUBMISSION: 10 December 2020 \\ ACCEPTED: 30 December 2020 \\ CORRESPONDENCE*: \\ yulianto@uib.ac.id \\ yockiefang@yahoo.co.id
}

AUTHOR'S ADDRESS:

Batam, Indonesia

\begin{abstract}
This research is to detect the factors that impact the purchase intention of "Halal" food and drink product consumer in Batam City. The Independent variables are Subjective Norm, Religiousity, Product Quality, Attitude as intervening variable and the dependent variable is Purchase intention. This research exploit consumer that look forward to buy "Halal" food and drink product ABC, Nestle, NESCAFE, and other brands. The adopted data was 330. Purposive Sampling was used as sampling method in this research, conclude there was a positive significant effect between the Subjective Norm, Religiousity, Product Quality and Attitude on Purchase Intention.
\end{abstract}

Keywords: Subjective norm, Religiousity, Product Quality, Attitude, Purchase Intention

\begin{abstract}
ABSTRAK
Penelitian ini bertujuan untuk mengetahui faktor-faktor yang mempengaruhi niat beli konsumen produk makanan dan minuman "Halal" di Kota Batam. Variabel bebasnya adalah Norma Subjektif, Religiusitas, Kualitas Produk, Sikap sebagai variabel intervening dan variabel terikat adalah Niat Beli. Penelitian ini mengeksploitasi konsumen yang ingin membeli produk makanan dan minuman "Halal" ABC, Nestle, NESCAFE, dan merek lain. Data yang diadopsi adalah 330. Purposive Sampling digunakan sebagai metode pengambilan sampel dalam penelitian ini, menyimpulkan terdapat pengaruh yang signifikan positif antara Norma Subjektif, Religiusitas, Kualitas Produk dan Sikap terhadap Niat Membeli.
\end{abstract}

Kata Kunci: $\quad$ Subjektif Norma, Keagamaan, Kualitas Produk, Sikap, Niat Pembelian 


\section{PENDAHULUAN}

Pada era dimana sektor ilmu pengetahuan dan teknologi mengalami inflasi yang pesat memicu kecakapan konsumen dalam merealisasikan keputusan selama membeli sebuah produk yang ditawarkan oleh produser. Produser memanfaatkan persoalan ini sebagai sarana dalam mengetahui keadaan serta produk yang beredar di pasar dengan tujuan produk yang dipromosikan memiliki dampak terhadap niat beli konsumen. Niat beli adalah unsur penting yang mempengaruhi konsumen dalam memilih terhadap berbagai macam pilihan di pasar berdasarkan pilihan mereka dalam perilaku pembelian konsumen (Kazmi \& Mehmood, 2016).

Kota Batam adalah salah satu kota Provinsi Kepulauan Riau yang memiliki tingkat laju pertumbuhan yang sangat tinggi di Indonesia dan merupakan kawasan pusat perdagangan bebas (Batam, Bintan, Karimun) sehingga berpengaruh terhadap tingkat daya beli yang tinggi secara nasional juga Provinsi Kepulauan Riau. Pemerintah Kota Batam juga ikut serta mendukung bidang-bidang penggerak ekonomi seperti komiditi ekspor ke negara lain tidak hanya konsumen Kota Batam dengan tujuan meningkatkan kesejahteraan dan kemakmuran masyarakat Kota Batam. Keadaan seperti ini dimanfaatkan oleh kompetitor-kompetitor mengetahui benefit seperti ini dapat mendukung dalam menggerakkan kegiatan ekonomi.

Sektor industri dan juga akademis menjadikan merek "Halal" sebagai subjek yang bersifat aktual untuk dibahas, mengingat Islam sebagai agama mayoritas di Kota Batam. Penganut agama Islam berjumlah $(71,14 \%)$ yang terdiri dari 1.037.187 jiwa penduduk kota, Kristen Protestan (18,51\%), Buddha (6,81\%), Katolik (3,32\%), Hindu (0,08\%), dan
Konghucu $(0,12 \%)$ (Badan Pengusahaan Batam).

"Halal" adalah sesuatu yang diizinkan dalam agama Islam, sedangkan segala sesuatu yang bukan dizinkan disebut "Haram". Agama Islam mengwajibkan penganutnya mengonsumsi produk "Halal". Ekspektasi dan motivasi yang diadopsi oleh konsumen dikatakan sebagai komponen Subjective Norm (Peter \& Olson, 2010).

Produk "Halal" telah menjadi tren dunia serta gaya hidup seseorang, dapat dikatakan bahwa pasar produk "Halal" baik pasar domestik dan global mempunyai potensi yang signifikan. Menurut Munir, (2012) evaluasi, perasaan dan kecenderungan individu yang relatif terhadap sebuah objek atau gagasan. Konsumen akan mencari produk yang mempunyai tanda sertifikasi "Halal" di saat mereka tidak bisa menemukan tanda sertifikasi "Halal" pada produk tertentu (Afendi, et. al, 2014). Konsumen akan mencari produk yang mempunyai tanda sertifikasi "Halal" di saat mereka tidak bisa menemukan tanda sertifikasi "Halal" pada produk tertentu. Prinsip Islam menjadikan merek "Halal" dalam mengarahkan sesuatu yang dizinkan seperti di sektor keuangan, kosmetik, makanan, busana, keramahtamahan serta perbankan (Alserhan, 2010). Penjualan produk "Halal" di Indonesia meningkat pada tahun 2018 dan menempati urutan pertama di antara 10 negara Muslim terbesar yaitu Turki, Pakistan, Mesir, Banglades, Iran, Arab Saudi, Nigeria, Rusia dan India dengan pendapatan sebesar 170 Miliar Dolar US (Global Islamic Economy Report 2018). Dalam hal tersebut sertifikasi "Halal" yang terdapat dalam produk menjadi sebuah syarat karena hampir sebagian besar produk makanan yang tersebar di Kota Batam memiliki sertifikat "Halal". 
Penelitian ini menggunakan brand yang memiliki popularitas tinggi sebagai instrumen penelitian yang meliputi $\mathrm{ABC}$ berjumlah $(21,8 \%)$, NESCAFE $(11,5 \%)$ dan NESTLE $(11,3 \%$ ) (Top Brand Award 2019). Berkaitan dengan ilustrasi yang dipaparkan di atas, membuka jalan terhadap pemula atau pengusaha bisnis dalam memasarkan produknya dengan sertifikat "Halal". Ada beberapa faktor yang mendorong konsumen untuk membeli produk bersertifikat "Halal" di Indonesia (Ozguven, 2012).

\section{Hubungan antara Subjective Norm terhadap Purchase Intention}

Norma subjektif didefinisikan sebagai opini yang dapat diidentifikasi dari orangorang yang sangat berpengaruh bagi seorang individu dalam pengambilan keputusan mereka. Alam \& Sayuti (2011) menyatakan bahwa variabel norma subjektif mempengaruhi niat pembelian produk "Halal" secara signifikan. Norma subjektif dan religiositas memberikan dampak positif terhadap sikap tentang produk "Halal" (Butt, 2012).

Norazah \& Salleh (2016) mengatakan konsumen diantispasi agar mengambil pandangan dari kelompok referensi mereka yang melindungi niat konsumen dalam membeli produk "Halal". Menurut (Kim, et.al, 2013) Keputusan setiap orang dalam melakukan sebuah perilaku dipengaruhi oleh pendapat orang-orang terdekat yang penting menurutnya diartikan sebagai norma subjektif. Norma subjektif menciptakan dampak dalam ketertarikan serta rela dalam melakukan pembelian ulang (Han \& Ryu, 2012).

\section{Hubungan antara Religiousity terhadap Purchase Intention}

Pada dasarnya agama diartikan sebagai praktik dan keimanan yang menganjurkan ketentuan serta kepuasan seseorang. Perilaku konsumen pada barang dan jasa sangat dipengaruhi oleh agama (Mukhtar \& Butt, 2012). Agama
Islam menjadi penentuan dalam niat pembelian terhadap produk yang memiliki label "Halal". Religiusitas memiliki dampak signifikan pada bentuk konsumsi konsumen berdasarkan penelitian sebelumnya (Cleveland, et. al, 2013). Berhubungan dengan konsumen Muslim, sebagian besar religiusitas berdampak terhadap adopsi sebuah produk baru (Rehman \& Shabbir, 2010). Alam, et. al, (2011) memberikan bukti bahwa Muslim menaati nilai-nilai Islam sebagai awal dalam melakukan pengeluaran yang masuk akal serta religiusitas memediasi interaksi variabel relatif dan kontekstual.

Bakar, et. al, (2013) mengungkapkan bahwa yang menjadi sorotan dalam komunitas Muslim adalah pengajaran tentang aspek-aspek kehidupan manusia serta aspek dalam mengonsumsi dan perilaku konsumen. Religiusitas dikatakan sebagai variabel yang memberikan dampak terhadap hubungan diantara beberapa faktor budaya dan niat beli terhadap suatu produk sebagai variabel independen serta variabel moderasi (Jamal \& Sharifuddin, 2015). Dikatakan demikian karena agama dianggap sebagai komponen budaya yang paling penting (Eid \& Gohary, 2015).

\section{Hubungan antara Product Quality terhadap Purchase Intention}

Kualitas produk adalah kombinasi karakteristik produk dari sebuah pemasaran, perencanaan, pembuatan dan pemeliharaan yang membuat produk yang digunakan dalam memenuhi harapan pelanggan secara menyeluruh (Marwanto $\&$ Aris, 2015). Anwar (2015) menyatakan produk yang didasari oleh kebutuhan serta keinginan dan diterima konsumen adalah konsep terpenting dalam membentuk sebuah produk yang mempunyai kualitas.

Perusahaan harus mampu dalam menghadapi tantangan terhadap permasalahan kualitas untuk memenangi persaingan pasar. Kualitas produk dan 
dimensi produk merupakan hal yang harus dikuasai oleh perusahaan agar mampu mengukur sejauh mana kualitas produk bisa memenuhi kebutuhan serta keinginan hingga kepuasan konsumen.

Kualitas dikatakan sebuah produk serta jasa yang melalui beberapa tahap proses seperti memperhitungkan nilai sebuah produk dan jasa tanpa ada kekurangan sedikitpun nilai produk dan jasa yang sesuai dengan harapan tinggi dari konsumen (Amrullah \& Agustin, 2016). Suatu fungsi tingkat kemampuan sebuah merek atau produk yang diharapkan terdefinisi sebagai kualitas produk (Assauri \& Sofjan, 2015).

Menurut Kotler \& Koller (2009) kualitas produk atau jasa dalam memuaskan kebutuhan yang tersirat tergantung pada fitur secara menyeluruh. Dapat disimpulkan bahwa kualitas produk merupakan seluruh ciri, karakteristik serta spesifikasi yang dimiliki sebuah barang atau jasa yang tergantung terhadap kemampuannya dalam memenuhi kebutuhan konsumen.

Menurut Pelau (2011) konsumen mempunyai perilaku yang berbeda-beda dikarenakan konsumen akan mencari, menggunakan, membeli dan timbul persepsi produk yang menjamin kebutuhan mereka. Kualitas produk dikatakan juga sebagai salah satu penyebab konsumen memiliki niat pembelian yang tinggi (Lee \& Yun, 2015). Zeeshan (2013) menyimpulkan bahwa kualitas merupakan hal yang berguna dalam menciptakan keunggulan yang kompetitif. Kualitas produk serta daya tarik sebuah iklan berdampak signifikan terhadap niat beli (Annafik, et. al, 2012).

\section{Hubungan antara Attitude terhadap Purchase Intention}

Sikap konsumen hanya didasarkan

pada kepercayaan dan pengetahuan barang dan diartikan sebagai hasil dari proses pengumpulan informasi yang mempengaruhi tujuan individu dalam berperilaku sikap tertentu. Sikap memiliki kecenderungan untuk bertindak dengan cara menguntungkan atau tidak (Awan, et. $a l$, 2015). Wilson \& Liu (2011) menyatakan bahwa makanan, budaya, diet serta agama memiliki hubungan yang kuat.

Sikap mempengaruh secara signifikan dan positif terhadap niat beli untuk membeli merek "Halal" (Azmawani, et. al, 2015). Scalco, et. al, (2017) menyatakan bahwa sikap dijadikan sebagai predikator utama dalam niat untuk membeli makanan tetapi di setiap studi korelasi ini berbeda. Keyakinan perilaku sangat penting untuk dipahami dalam menentukan sikap suka dan tidak suka konsumen terhadap produk yang memiliki merek "Halal" (Haque, et. al, 2015). Menurut Porter \& Norris (2010) dalam sebuah hubungan, sikap menjadi moderator yang signifikan.

Bagi umat Islam sertifikasi "Halal" merupakan hal yang penting dikarenakan dalam ajaran Islam diharuskan untuk mengkonsumsi makanan "Halal" (Golnaz, et. al, 2010). Menurut Norazah \& Sulaiman (2016) penelitian sebelumnya menunjukkan bahwa sikap merupakan hubungan yang berdampak secara signifikan positif dalam niat beli terhadap pembelian merek "Halal". Perlu diketahui bahwa perilaku keyakinan sebagai penentuan sikap suka atau tidak konsumen terhadap produk-produk bermerek "Halal" (Haque, et. al, 2015).

\section{Hubungan antara Subjective Norm terhadap Attitude}

Norma subjektif terbukti memberikan pengaruh terhadap sikap dan niat konsumen Muslim untuk membeli produk "Halal" (Lada, et. al, 2009). Persepsi kemudahan dalam menggunakan serta kegunaan mempunyai hubungan positif yang kuat (Son, et. al, 2012). Mukhtar \& Butt (2012) menyatakan 
berdasarkan Theory of Reasoned Action (TRA) ditemukan bahwa sikap dan norma subyektif memiliki hubungan positif mengenai niat konsumen dalam memilih produk "Halal".

Konsumen bertindak sesuatu karena mengadopsi ekspetasi dan pendapat orang lain (Peter \& Olson, 2010). Menurut Parra, et. al, (2014) dalam proses produksi, reproduksi produk baru dianggap sebagai penggantian produk bekas menjadi baru dengan memiliki jaminan yang sama. Adanya hubungan positif yang kuat dalam penggunaan serta kegunaan pada penelitian sebelumnya (Son, et. al, 2012).

\section{Hubungan antara Religiousity terhadap Attitude}

Shukor \& Jamal (2013) mengatakan bahwa agama diartikan sebagai fungsi etis utama pada kehidupan. Ketika seseorang membangun sikap dan perilaku, agama bertindak sebagai fondasi (Mukhtar \& Butt, 2012). Souiden \& Rani (2015) menyatakan bahwa sikap sebagai mediator religiusitas dalam mempengaruhi niat beli secara tidak langsung. Peran moderasi dari religiusitas adalah nilai hubungan antara dimensi tradisional, nilai dimensi Islam dan kepuasan konsumen terhadap layanan (Eid \& Gohary, 2015).

Cleveland \& Chang, (2009) mengatakan bahwa konsep kehidupan religiusitas sebagai pusat dimana manusia dengan aktivitas sehari-hari yang sebenarnya. Bakar, et. al, (2013) mengetahui bahwa konsumen dengan tingkat religiusitas tinggi lebih menyarankan produk kemasan yang memiliki simbol Islam kepada konsumen lainnya dalam pembelajaran dampak simbol Islam pada produk kemasan pada niat beli konsumen Muslim. Religiusitas memiliki peranan yang signifikan dalam membentuk sifat seorang konsumen terhadap produk dan layanan (Mukhtar \& Butt, 2011).

\section{Hubungan antara Product Quality terhadap Attitude}

Penelitian sebelumnya mengungkapkan bahwa adanya keterkaitan antara kualitas produk dan sikap konsumen. Kualitas produk disimpulkan sebagai kelebihan barang dalam menciptakan hasil yang sesuai serta melebihi dari keinginan konsumen (Kotler \& Keller, 2009). Kesimpulan yang diterima adalah produk yang memiliki kualitas merupakan produk yang sesuai dengan kebutuhan serta keinginan konsumen.

Menurut penelitian (Chi, et. al, 2009) kualitas produk mempengaruhi niat konsumen untuk membeli secara signifikan.

Amrullah \& Agustin (2016) menyatakan bahwa sebuah produk dan jasa yang dilalui tahap-tahap proses yaitu memperhitungkan produk serta jasa tanpa kekurangan sedikitpun dari nilai suatu produk dan jasa yang menciptakan produk dan jasa sesuai harapan konsumen yang tinggi. Pengukuran terhadap produk food and beverage terdapat 5 indikator yakni produk yang mempunyai rasa enak, higenisnya sebuah produk, porsi yang sesuai, kemasan praktis serta menarik dan memiliki aroma enak (Yesenia \& Siregar, 2014).

Pramono (2011) mengungkapkan bahwa terdapat 4 nilai dalam persepsi kualitas yaitu alasan dalam membeli, diferensiasi, harga optimum dan minat saluran distribusi. Dalam mengukur kualitas produk terdapat 4 hal yang harus diperhatikan yang meliputi keserasian, reliabilitas, kehandalan serta keunggulan (Wang \& Tsai, 2014). Menurut Jaafar, et. al (2012) nilai yang baik seperti persepsi konsumen dan penilaian sikap mencipkan hasrat untuk membeli. 
Hubungan antara Subjective Norm terhadap Purchase Intention dengan Attitude sebagai Variabel Mediasi

Wu \& Chen (2014) memprediksi perilaku seseorang mempunyai keterkaitan yang kuat dengan suatu kelompok yang menjadi referensinya. Adanya hubungan yang erat antara norma subjektif dengan sikap (Irianto, 2015). Menurut (Yang \& Jolly, 2009) persepsi tekanan sosial seseorang menciptakan cara tertentu. Liang \& Lim (2011) menyatakan bahwa norma subjektif berdampak positif terhadap niat perilaku.

\section{Hubungan antara Religiousity terhadap Purchase Intention dengan Attitude sebagai Variabel Mediasi}

Aman, et. al, (2011) memaparkan bahwa umat Muslim mematuhi nilai islam sebagai sumber referensi sebelum memutuskan pengeluaran yang masuk akal dan religiusiatas menjadi mediasi hubungan antara variabel-variabel yang bersifat kontekstual. Farrag \& Hassan (2015) mengungkapkan bahwa agama sebagai institusi sosial yang universal dan berdampak besar pada sikap, nilai dan perilaku seorang individu dan masyarakat. Religiusitas memiliki dampak yang signifikan terhadap niat pembelian pada penelitian sebelumnya (Tabassy, 2012).

Hubungan antara Product Quality terhadap Purchase Intention dengan Attitude sebagai Variabel Mediasi

Kualitas produk dikatakan sebagai kelebihan sebuah produk dalam menerapkan sebuah keadaan (Abdullah \& Tantri, 2014). Beneke, et. al, (2013) menganalisa dampak dari kualitas produk pada nilai dan niat beli private label merchandise. Penganalisaan terdahulu mengatakan bahwa kualitas produk berdampak signifikan terhadap niat beli (Beneke, et. al, 2013).

\section{Model Penelitian dan Perumusan Hipotesis}

Adapun beberapa perumusan hipotesis sebagai berikut:

H1: Subjective Norm berdampak signifikan terhadap Purchase Intention.

$\mathrm{H} 2$ : Religiousity berdampak signifikan terhadap Purchase Intention.

H3: Product Quality berdampak signifikan terhadap Purchase Intention.

H4: Attitude berdampak signifikan terhadap Purchase Intention.

H5: Subjective Norm berdampak signifikan terhadap Attitude.

H6: Religiousity berdampak signifikan terhadap Attitude.

H7: Product Quality berdampak signifikan terhadap Attitude.

H8: Subjective Norm berdampak signifikan terhadap Purchase Intention dengan Attitude sebagai variabel mediasi.

H9: Religiousity berdampak signifikan terhadap Purchase Intention dengan Attitude sebagai variabel mediasi.

H10: Product Quality berdampak signifikan terhadap Purchase Intention dengan Attitude sebagai variabel mediasi.

\section{METODE PENELITIAN}

\section{Rancangan Penelitian}

Rancangan penelitian ini termasuk jenis penelitian kuantitatif, yaitu metode penelitian yang berlandaskan terhadap filsafat positivisme, digunakan dalam meneliti terhadap sample dan populasi penelitian. Pengumpulan data dilakukan dengan cara memanfaatkan instrumen penelitian yang dipakai, analisis data yang digunakan bersifat kuantitatif/bisa diukur dengan tujuan untuk menguji hipotesis yang ditetapkan sebelumnya (Sugiyono, 2015).

Dalam observasi ini terdapat beberapa variabel independen yang meliputi Subjective Norm, Religiousity, 
Product Quality, Attitude dan Purchase Intention sebagai variabel dependen. Penyebaran kuesioner akan disebarkan kepada masyarakat yang berdomisili di Kota Batam yang bertujuan menggalang data untuk observasi ini.

\section{Objek Penelitian}

Penelitian ini memanfaatkan konsumen yang mengkonsumsi produk makanan dan minuman "Halal" di Kota Batam sebagai sample. Populasi observasi yang akan diteliti adalah konsumen produk makanan dan minuman di Kota Batam. Populasi adalah keseluruhan dari subjek penelitian (Arikunto, 2013). Pengumpulan data menggunakan instrumen penelitian, analisis data bersifat kuantitatif/statistik dengan tujuan untuk menguji hipotesis yang telah diterapkan (Sugiyono, 2012). Penulis menetapkan responden Kota Batam secara acak serta memonitor proses pengisian kuesioner dalam observasi ini.

\section{HASIL DAN PEMBAHASAN}

\section{Common Method Biases}

Penelitian ini menganalisa hasil uji dengan memanfaatkan program SmartPLS 3.0 dalam memutuskan tingkat variance teknik data yang dimiliki. Analisa ini menghasilkan nilai variance yang berjumlah $34,508 \%$ yang menyatakan di bawah nilai $50 \%$, nilai variance lebih kecil dari 50\% karena data yang dikumpulkan diperoleh dari responden yang mengkonsumsi produk makanan dan minuman "Halal" di Kota Batam. Hasil uji menyatakan bahwa Common Method Biases dalam analisa tersebut tidak terjadi.

\section{Uji Validitas}

Uji validitas memakai dasar penghubung pada setiap skor item atau total skor yang didapat atas jawaban responden dalam kuesioner. Menurut Ghozali, et. al, (2012) butir pertanyaan dikatakan valid jika nilai AVE lebih besar dari 0.50. Berikut hasil uji validitas seperti di bawah ini:

Tabel 1

Data Hasil Uji Validitas

\begin{tabular}{lcc}
\hline Variabel & AVE & Kesimpulan \\
\hline Attitude & 0.750 & Valid \\
Purchase Intention & 0.853 & Valid \\
Product Quality & 0.838 & Valid \\
Religiousity & 0.761 & Valid \\
Subjective Norm & 0.957 & Valid \\
\hline
\end{tabular}

Sumber: Hasil data primer (2019)

Nilai variabel Attitude

memperlihatkan nilai AVE lebih besar dari 0.50 yakni sebesar 0.750 dan dapat disimpulkan bahwa variabel Attitude dinyatakan valid serta sesuai syarat konvergen (Ghozali, et. al, 2012). Variabel Purchase Intention menunjukkan nilai AVE berada diatas 0.50 yaitu sejumlah 0.853 dan dapat disimpulkan bahwa variabel Purchase Intention dikatakan valid karena sesuai dengan syarat konvergen (Ghozali, et. al, 2012).

Variabel Product Quality memaparkan nilai AVE berada diatas 0.50 yang sebesar 0.838 dan disimpulkan bahwa variabel Product Quality dinyatakan valid juga berdasarkan syarat konvergen (Ghozali, et. al, 2012). Variabel Religiousity menunjukkan nilai AVE berada diatas 0.50 yaitu berjumlah 0.761, sehingga berdasarkan hasil akhir mampu disimpulkan bahwa variabel Religiousity valid dan memenuhi persyaratan konvergen (Ghozali, et. al, 2012).

Nilai Variabel Subjective Norm memperlihatkan nilai AVE lebih besar dari 0.50 yaitu sebesar 0.957 dan disimpulkan bahwa variabel Subjective Norm dikatakan valid serta sesuai dengan syarat konvergen (Ghozali, et. al, 2012).

\section{Uji Reliabilitas}

Uji reliabilitas memakai dasar pengambilan keputusan yang sudah ditentukan oleh para ahli. Nilai Composite Reliability dikatakan reliabel jika di atas 0.70 (Hair, et. al, 2010). Hasil uji reliabilitas seperti berikut: 
Tabel 2

Data Hasil Uji Reliabilitas

\begin{tabular}{lcc}
\hline Variabel & Composite Reliability & Keterangan \\
\hline Attitude & 0.937 & Reliabel \\
Purchase Intention & 0.959 & Reliabel \\
Product Quality & 0.939 & Reliabel \\
Religiousity & 0.941 & Reliabel \\
Subjective Norm & 0.957 & Reliabel \\
\hline
\end{tabular}

Sumber: Hasil data primer (2019)

Nilai variabel Attitude memperlihatkan nilai Composite Reliability lebih besar dari 0.70 yakni sebesar 0.937 dan dapat disimpulkan bahwa variabel Attitude dinyatakan reliabel (Hair, et. al, 2010). Variabel Purchase Intention menunjukkan nilai Composite Reliablity berada diatas 0.70 yaitu sejumlah 0.959 dan dapat disimpulkan bahwa variabel Purchase Intention dikatakan reliabel (Hair, et. al, 2010). Variabel Product Quality memaparkan nilai Composite Reliablity berada diatas 0.70 yang sebesar 0.939 dan disimpulkan bahwa variabel Product Quality dinyatakan reliabel (Hair, et. al, 2010). Variabel Religiousity menunjukkan nilai Composite Reliability berada diatas 0.70 yaitu berjumlah 0.941 , sehingga berdasarkan hasil akhir mampu disimpulkan bahwa variabel Religiousity reliabel (Hair, et. al, 2010).

Nilai Variabel Subjective Norm memperlihatkan nilai Composite Reliablity lebih besar dari 0.70 yaitu sebesar 0.957 dan disimpulkan bahwa variabel Subjective Norm dikatakan reliabel (Hair, et. al, 2010).

\section{Uji Inner Model}

\section{Hasil Uji Model Struktural Tanpa Mediasi}

Hasil Uji Pengaruh Langsung tanpa mediasi. Tabel 3 dibawah ini memperlihatkan perhitungan uji signifikansi antara variabel independen, Subjective Norm, Religiousity dan Product Quality terhadap Purchase Intention. Tabel 3 memperlihatkan bahwa (1) adanya pengaruh signifikan positif antara hubungan variabel independen Subjective Norm terhadap Purchase
Intention dengan nilai T-Statistic 4.301 dan di atas 1.96 dengan probabilitas 5\% (0.05) (Khalek, 2012) sedangkan (Garg \& Joshi, 2018) menyatakan pengaruh signifikan negatif. (2) Nora \& Minarti, (2016) menyimpulkan bahwa variabel independen Religiousity terhadap Purchase Intention terjadi signifikan positif dengan nilai T-Statistic 3.347 atau lebih besar dari 1.96 dengan probabilitas 5\% (0.05) sedangkan Garg \& Joshi (2018) mengatakan terjadinya signifikan negatif. (3) variabel independen Product Quality terhadap Purchase Intention dengan nilai T-Statistic 4.829 atau lebih besar dari 1.96 dengan probabilitas 5\% (0.05). (1) adanya pengaruh signifikan positif antara hubungan variabel independen Attitude terhadap Purchase Intention dengan nilai T-Statistic 6.907 dan di atas 1.96 dengan probabilitas 5\% (0.05). Data hasil uji pengaruh langsung tanpa mediasi disajikan seperti berikut ini:

Tabel 3

Data Hasil Uji Pengaruh Langsung Tanpa Mediasi

\begin{tabular}{lccc}
\hline \multicolumn{1}{c}{ Jalur } & $\begin{array}{c}\text { Sample } \\
\text { Mean }\end{array}$ & T-Statistic & Kesimpulan \\
\cline { 1 - 2 } $\begin{array}{l}\text { Subjevtive Norm } \rightarrow \text { Purchase } \\
\text { Intention }\end{array}$ & 0.220 & 4.301 & H1: Signifikan Positif \\
$\begin{array}{l}\text { Religiousity } \rightarrow \text { Purchase } \\
\text { Intention }\end{array}$ & 0.136 & 3.347 & H2:Signifikan Negatif \\
$\begin{array}{l}\text { Product Quality } \rightarrow \text { Purchase } \\
\text { Intention }\end{array}$ & 0.240 & 4.829 & H3: Signifikan Positif
\end{tabular}

Sumber: Hasil data primer (2019)

\section{Uji Model Struktural Dengan Mediasi}

Uji model struktural dengan mediasi ini dilakukan dalam mengkaji peran variabel mediasi dan variabel independen dengan variabel dependen Purchase Intention. Pengujian model secara simultan menghasilkan nilai signifikan pada hubungan antara (1) variabel independen Subjective Norm dengan variabel mediasi Attitude, (2) variabel independen Religiousity dengan variabel mediasi Attitude menghasilkan nilai signifikan (Garg \& Joshi, 2018) 
sedangkan Putri, et. al, (2018) menyatakan tidak menghasilkan nilai signifikan (3) variabel independen Product Quality dengan variabel mediasi Attitude menghasilkan nilai signifikan. (4) Variabel mediasi sendiri yaitu Attitude menghasilkan pengaruh hubungan dengan Purchase Intention dengan nilai signifikasi atau T-Statistic sebesar 6.907. Di bawah ini adalah hasil uji pengaruh secara tidak langsung beserta variabel mediasi Attitude:

Tabel 4

Data Hasil Uji Pengaruh Tidak Langsung Dengan Variabel Mediasi Terhadap Variabel Dependen

\begin{tabular}{lccl}
\hline $\mathrm{M} \rightarrow \mathrm{Y}(\mathrm{b}) /$ Indirect effect & $\begin{array}{c}\text { Sample T-Statistic } \\
\text { Mean }\end{array}$ & Kesimpulan \\
\hline Attitude $\rightarrow$ Purchase Intention & 0.408 & 6.907 & H4: Signifikan
\end{tabular}

Sumber: Hasil data primer (2019)

Tabel 5

Data Hasil Uji Model Struktural Tidak Langsung Dengan Mediasi

\begin{tabular}{lccc}
\hline \multicolumn{1}{c}{ Jalur } & $\begin{array}{c}\text { Sample } \\
\text { Mean }\end{array}$ & T-Statistic & Kesimpulan \\
\cline { 1 - 3 } \multicolumn{1}{c}{ Subjevtive (a) / Indirect Effect $\rightarrow$ Attitude } & 0.511 & 9.140 & H5: Signifikan Positif \\
Religiousity $\rightarrow$ Attitude & 0.085 & 1.748 & H6:Signifikan Negatif \\
Product Quality $\rightarrow$ Attitude & 0.361 & 6.467 & H7: Signifikan Positif
\end{tabular}

Sumber: Hasil data primer (2019)

Tabel 6

Data Hasil Uji Pengaruh Langsung

Dengan Variabel Mediasi

\begin{tabular}{|c|c|c|c|}
\hline $\begin{array}{l}\mathrm{X} \rightarrow \mathrm{Y}\left(\mathrm{c}^{\prime}\right) / \text { Direct effect with } \\
\text { mediation }\end{array}$ & Beta & T-Statistic & Kesi \\
\hline $\begin{array}{l}\text { Subjective Norm } \rightarrow \text { Attitude } \rightarrow \\
\text { Purchase Intention }\end{array}$ & 0.209 & 5.814 & H8: Signifikan \\
\hline $\begin{array}{l}\text { Religiousity } \rightarrow \text { Attitude } \rightarrow \text { Purchase } \\
\text { Intention }\end{array}$ & 0.034 & 1.774 & H9: Signifikan \\
\hline $\begin{array}{l}\text { Product Quality } \rightarrow \text { Attitude } \rightarrow \\
\text { Purchase Intention }\end{array}$ & 0.148 & 4.469 & Hl0: Signifikan \\
\hline
\end{tabular}

Sumber: Hasil data primer (2019)

\section{Hasil Pengujian Hipotesis}

\section{H1: Subjective Norm berpengaruh positif terhadap Purchase Intention \\ Hasil uji pengaruh langsung tanpa} mediasi pada Tabel 3 menunjukkan variabel Subjective Norm terhadap Purchase Intention memiliki dampak signifikan dengan T-Statistic variabel Subjective Norm berjumlah 4.301 atau lebih besar dari nilai 1.96 yang berarti variabel Subjective Norm memiliki dampak signifikan positif terhadap Purchase Intention. Adanya hubungan signifikan antara Subjective Norm dan Purchase Intention dan terbukti bahwa analisa hipotesis 1 dapat diterima. Hasil dari pengkajian ini konsisten dengan penelitian dari Khalek (2012), Mukthar \& Butt (2012), Basha, et. al, (2015), Irianto (2015), Tseng \& Chang (2015), Dehyadegari, et. al, (2016), Endah, et. al, (2017), Rezai, et. al, (2017), Weng, et. al, (2017), Al-Swidi, et. al, (2018) dan Nam, et. al, (2019).

\section{H2: Religiousity berpengaruh positif terhadap Purchase Intention \\ Hasil uji pengaruh langsung tanpa} mediasi pada Tabel 3 menunjukkan variabel Religiousity terhadap Purchase Intention memiliki dampak signifikan dengan T-Statistic variabel Religiousity berjumlah 3.347 atau lebih besar dari nilai 1.96 yang berarti variabel Religiousity memiliki dampak signifikan positif terhadap Purchase Intention. Adanya hubungan signifikan antara Religiousity dan Purchase Intention dan terbukti bahwa analisa hipotesis 2 dapat diterima. Hasil dari pengkajian ini konsisten dengan penelitian dari Dehyadegari, et. al, (2016), Nora \& Minarti (2016), Putri, et. al, (2018).

\section{H3: Product Quality berpengaruh positif terhadap Purchase Intention}

Hasil uji pengaruh langsung tanpa mediasi pada tabel 3 menunjukkan variabel Product Quality terhadap Purchase Intention memiliki dampak signifikan dengan T-Statistic variabel Product Quality berjumlah 4.829 atau lebih besar dari nilai 1.96 yang berarti variabel Product Quality memiliki 
dampak signifikan positif terhadap Purchase Intention. Adanya hubungan signifikan antara Product Quality dan Purchase Intention dan terbukti bahwa analisa hipotesis 3 dapat diterima. Hasil dari pengkajian ini konsisten dengan penelitian dari Basha, et. al, (2015).

\section{H4: Attitude berpengaruh positif terhadap Purchase Intention}

Hasil uji pengaruh tidak langsung dengan variabel mediasi terhadap variabel dependen pada Tabel 4 menunjukkan variabel Attitude terhadap Purchase Intention memiliki dampak signifikan dengan T-Statistic variabel Purchase Intention berjumlah 6.907 atau lebih besar dari nilai 1.96 yang berarti variabel Attitude memiliki dampak signifikan positif terhadap Purchase Intention. Adanya hubungan signifikan antara Attitude dan Purchase Intention dan terbukti bahwa analisa hipotesis 4 dapat diterima. Hasil dari pengkajian ini konsisten dengan penelitian dari Nora \& Minarti (2016), Putri, et. al, (2018).

\section{H5: Subjective Norm berpengaruh positif terhadap Attitude}

Data hasil uji model struktural tidak langsung dengan mediasi pada Tabel 5 menunjukkan variabel Subjective Norm terhadap Attitude memiliki dampak signifikan dengan T-Statistic variabel Subjective Norm berjumlah 9.140 atau lebih besar dari nilai 1.96 yang berarti variabel Subjective Norm memiliki dampak signifikan positif terhadap Attitude. Adanya hubungan signifikan antara Subjective Norm dan Attitude dan terbukti bahwa analisa hipotesis 5 dapat diterima. Hasil dari pengkajian ini konsisten dengan penelitian dari Khalek (2012), Garg \& Joshi (2018).

\section{H6: Religiousity berpengaruh negatif terhadap Attitude \\ Data hasil uji model struktural} tidak langsung dengan mediasi pada Tabel 5 menunjukkan variabel Religiousity terhadap Attitude memiliki dampak tidak signifikan dengan T-Statistic variabel
Religiousity berjumlah 1.748 atau lebih kecil dari nilai 1.96 yang berarti variabel Religiousity memiliki dampak signifikan negatif terhadap Attitude. Adanya hubungan tidak signifikan antara Religiousity dan Attitude dan terbukti bahwa analisa hipotesis 6 tidak dapat diterima. Hasil dari pengkajian ini konsisten dengan penelitian dari Quoquab, et. al, (2015) dan Putri, et. al, (2018).

H7: Product Quality berpengaruh positif terhadap Attitude

Data hasil uji model struktural tidak langsung dengan mediasi pada Tabel 5 menunjukkan variabel Product Quality terhadap Attitude memiliki dampak signifikan dengan T-Statistic variabel Product Quality berjumlah 6.467 atau lebih besar dari nilai 1.96 yang berarti variabel Product Quality memiliki dampak signifikan positif terhadap Attitude. Adanya hubungan signifikan antara Product Quality dan Attitude dan terbukti bahwa analisa hipotesis 7 dapat diterima. Hasil dari pengkajian ini konsisten dengan penelitian dari Basha, et . al, (2015).

\section{Hs: Subjective Norm berpengaruh positif terhadap Purchase Intention dengan variabel mediasi Attitude}

Data hasil uji pengaruh langsung dengan variabel mediasi pada Tabel 6 menunjukkan variabel Subjective Norm terhadap Purchase Intention dengan variabel Attitude sebagai variabel mediasi memiliki dampak signifikan dengan $T$ Statistic variabel Subjective Norm terhadap Purchase Intention dengan variabel Attitude sebagai variabel mediasi berjumlah 5.814 atau lebih besar dari nilai 1.96 yang berarti variabel Subjective Norm terhadap Purchase Intention dengan variabel Attitude sebagai variabel mediasi memiliki dampak signifikan positif terhadap Attitude. Adanya hubungan signifikan antara Subjective Norm dan Purchase Intention dengan Attitude 
sebagai variabel mediasi dan terbukti bahwa analisa hipotesis 8 dapat diterima. Hasil dari pengkajian ini konsisten dengan penelitian dari Basha, et. al, (2015).

H9: Religiousity berpengaruh positif terhadap Purchase Intention dengan variabel mediasi Attitude

Data hasil uji pengaruh langsung dengan variabel mediasi pada Tabel 6 menunjukkan variabel Religiousity terhadap Purchase Intention dengan variabel Attitude sebagai variabel mediasi memiliki dampak tidak signifikan dengan T-Statistic variabel Religiousity terhadap Purchase Intention dengan variabel Attitude sebagai variabel mediasi berjumlah 1.774 atau lebih kecil dari nilai 1.96 yang berarti variabel Religiousity terhadap Purchase Intention dengan variabel Attitude sebagai variabel mediasi memiliki dampak signifikan negatif terhadap Attitude. Adanya hubungan tidak signifikan antara Religiousity dan Purchase Intention dengan Attitude sebagai variabel mediasi dan terbukti bahwa analisa hipotesis 9 tidak dapat diterima. Hasil dari pengkajian ini konsisten dengan penelitian dari Nora \& Minarti (2016).

H10: Product Quality berpengaruh positif terhadap Purchase Intention dengan variabel mediasi Attitude

Data hasil uji pengaruh langsung dengan variabel mediasi pada Tabel 6 menunjukkan variabel Product Quality terhadap Purchase Intention dengan variabel Attitude sebagai variabel mediasi memiliki dampak signifikan dengan $T$ Statistic variabel Quality Product terhadap Purchase Intention dengan variabel Attitude sebagai variabel mediasi berjumlah 4.469 atau lebih besar dari nilai 1.96 yang berarti variabel Product Quality terhadap Purchase Intention dengan variabel Attitude sebagai variabel mediasi memiliki dampak signifikan positif terhadap Attitude. Adanya hubungan signifikan antara Product Quality dan Purchase Intention dengan Attitude sebagai variabel mediasi dan terbukti bahwa analisa hipotesis 10 dapat diterima. Hasil dari pengkajian ini konsisten dengan penelitian dari Quah \& Tan (2009), Ozguven (2012) dan Basha, et. al, (2015).

\section{Uji Koefisien Determinasi $\left(\mathbf{R}^{\mathbf{2}}\right)$}

Uji Koefisien Determinasi $\left(\mathrm{R}^{2}\right)$ memakai dasar kuadrat koefisien determinasi. Variabel mediasi Attitude memiliki nilai sebesar $0,764 \quad(76,4 \%)$ dengan pengertian bahwa variabel independen, Subjective Norm, Religiousity dan Product Quality mampu menjelaskan variabel mediasi Attitude sebanyak 76,40\%. Sedangkan untuk $23,6 \%$ lainnya dijelaskan oleh faktor atau variabel lain yang tidak diteliti dalam penelitian ini. Hasil pengujian Koefisien Determinasi $\left(\mathrm{R}^{2}\right)$ seperti berikut ini:

Tabel 7

Data Hasil Uji Koefisien Determinasi $\left(R^{2}\right)$ Subjective Norm, Religiousity dan Product Quality Terhadap Attitude

\begin{tabular}{ccc}
\hline Variabel & RSquare Adjusted & Kesimpulan \\
\hline Attitude & 0,764 & Large
\end{tabular}

Sumber: Hasil data primer (2019)

Tabel 7 memaparkan bahwa hasil uji R Square Adjusted variabel dependen yaitu Purchase Intention berjumlah 0,822 (82.2\%) dan disimpulkan bahwa variabel mediasi Attitude mampu mendeskripsikan variabel dependen Purchase Intention dengan jumlah $82,2 \%$. Jumlah $17,8 \%$ yang lain merupakan penyebab atau variabel lain yang tidak dikaji dalam penelitian ini. Berikut merupakan hasil uji $\mathrm{R}$ Square variabel mediasi terhadap variabel dependen seperti di bawah ini: Tabel 8

Data Hasil Uji Koefisien Determinasi $\left(R^{2}\right)$ Attitude Terhadap Purchase Intention 


\begin{tabular}{ccc}
\hline Variabel & R Square Adjusted & Kesimpulan \\
\hline Purchase Intention & 0,822 & Large \\
\hline
\end{tabular}

Sumber: Hasil data primer (2019)

\section{Uji Quality Index}

Uji Quality Index memakai dasar Goodness of Fit dengan bantuan software PLS. Goodness of Fit dikatakan sebagai perbedaan model yang dispesifikasi dengan matriks kovarian antar indikator (Ghozali \& Latan, 2012). Tabel 4.14 menunjukkan bahwa nilai $G o F$ yang dihasilkan lebih besar dari 0,36, maka dapat disimpulkan bahwa $G o F$ termasuk dalam kategori besar yang berarti model tersebut baik dan dapat digunakan dalam penelitian (Fornel \& Larcker, 1981; Cohen, 1988; Ghozali \& Latan, 2012). Hasil uji nilai Goodness of Fit untuk variabel independen terhadap variabel mediasi dapat dilihat pada Tabel dibawah ini:

Tabel 9

Data Hasil Uji Goodness Of Fit

Terhadap Attitude

\begin{tabular}{lcc}
\hline Variabel & GoF & Kesimpulan \\
\hline Attitude & 0,756 & Large \\
\hline
\end{tabular}

Sumber: Hasil data primer (2019)

\section{Hasil Uji Goodness of Fit}

Hasil uji nilai Goodness of Fit pada variabel mediasi terhadap variabel dependen menunjukkan bahwa nilai $G o F$ yang dihasilkan lebih besar dari 0.36, dapat disimpulkan bahwa $G o F$ termasuk kategori besar yang memiliki arti bahwa model tersebut positif dan dapat digunakan dalam penelitian (Ghozali dan Latan, 2012). Di bawah ini merupakan uji GoF seperti berikut:

Tabel 10

Hasil Uji Goodness of Fit terhadap

Purchase Intention

\begin{tabular}{lcc}
\hline Variabel & GoF & Kesimpulan \\
\hline Purchase Intention & 0,837 & Large \\
\hline
\end{tabular}

Sumber: Hasil data primer (2019)

\section{SIMPULAN}

Penelitian ini memberikan dampak yang sangat besar bagi pemilik usaha untuk mempertimbangakan perilaku konsumen terkait dengan makanan halal, tentunya hasil penelitian ini memberikan dampak yang sangat baik bagi pengusaha yang sedang mengembangkan destinasi wisata halal. Beberapa saran dalam penelitian berdasarkan temuan lapangan dan penyesuaian hasil temuan yaitu sebagai berikut:

1. Bagi peneliti selanjutnya dapat mengkaji produser dan konsumen produk lain yang tidak dikaji dalam penelitian ini.

2. Variabel Independen Subjective Norm menunjukkan hubungan signifikan positif terhadap Purchase Intention, oleh karena itu penulis berharap produser mengantisipasi dalam mengambil niat konsumen untuk melindungi niat konsumen dalam melakukan pembelian.

3. Variabel independen Product Quality menunjukkan hubungan signfikan positif terhadap variabel dependen Purchase Intention, oleh karena itu penulis berharap produser menempatkan kualitas produk sebagai prioritas dalam melakukan penjualan.

4. Mengingat Agama Islam merupakan agama yang mempunyai populasi yang sangat besar di Indonesia, maka penulis berharap produser baru atau lama mendaftarkan sertifikasi "Halal" pada produk yang dipasarkan.

\section{DAFTAR PUSTAKA}

Arshia Mukhtar., \& Mohsin Muhammad Butt. 
(2012). Intention to choose halal products the role of

religiosity. Journal of Islamic Marketing, 31, 1-11.

Annafik., Aldan., \& Faikar. (2012). "Analisis Pengaruh Kualitas Produk, Harga dan Daya Tarik Iklan Terhadap Minat Beli Sepeda Motor Yamaha”. Diponegoro Journal of Management, 1 (2), 274-281.

Azmawani, A.R., Ebrahim, A., \& Suhaimi, A.R. (2015). "Consumers and halal cosmetic products: knowledge, religiosity, attitude and intention". Journal of Islamic Marketing, 6 (1).

Assauri., \& Sofjan. (2015). Manajemen Pemasaran, Jakarta: Rajawali Pers.

Awan, H. M., Siddiquei, A. N., \& Haider, Z. (2015). Factors affecting Halal purchase intention-evidence from Pakistan's Halal Food Sector. Management Research Review, 23.

Amrullah, A. R., \& Agustin, S. (2016). Pengaruh Kualitas Produk, Harga, dan Citra Merek Terhadap Keputusan Pembelian Honda Beat. Jurnal Ilmu dan Riset Manajemen, 5 (7).

Anwar, I. (2015). Pengaruh Harga dan Kualitas Produk Terhadap Keputusan Pembelian. Jurnal Ilmu dan Riset Manajemen, 4 (12).

Abdulrazak., Rula M. Al., Gbadamosi., \& Ayantunji. (2017). Trust, religiosity, and relationship marketing: a conceptual overview of consumer brand loyalty. Society and Business Review, 12 (3), 320339.

Abdullah., Thamrin., \& Francis Tantri. (2015). Manajemen Pemasaran, Jakarta: Raja Grafindo Persada.

Abdullah., \& Tantri. (2014). Manajemen Pemasaran. Depok: Rajagrafindo Persada.
Bakar, A. R., Lee \& C. Rungie. (2013). The effects of religious symbols in product packaging on Muslim consumer responses, Australia: Marketing J, 21, 198-204.

Beneke, J., Flynn. R., Greig, T, Mukaiwa, M. (2013). The influence Of Perceived Product Quality, Relative Price And Risk On Customer Value And Willingness To Buy: A Study Of Private Label Merchandise. Journal Of Product \& Brand Management. 22 (3).

Cleveland, M., Laroche, M., Hallab, R. (2013). Globalization, culture, religion, and values: comparing consumption patterns of Lebanese Muslims and Christians. Journal of Business Research, 66 (8), 958-967.

Durianto, Darmadi. (2011). Strategi Menaklukkan Pasar Melalui Riset Ekuitas dan Perilaku Merek. 20, Jakarta: PT. Gramedia Pustaka Utama.

Eid, R., \& Gohary, H.E. (2015). The role of Islamic religiosity on the relationship between perceived value and tourist satisfaction. Tourism Manage, 46, 477488.

Fabrigar, L. R., Porter, R. D., \& Norris, M. E. (2010). Some things you should know about structual equation modeling but never thought to ask. Journal of Consumer Psychology, 20 (2), 221-225.

Farrag, D. A., \& Hassan, M. (2015). The influence of Religiosity on Egyptian Muslim Youth's Attitude Towards Fashion. Journal of Islamic Marketing. 6 (1), 95-108.

Ghozali., \& Imam. (2011). Structual Equation Modeling Metode Alternatif Dengan Partial Least Square (PLS), 3, Semarang: Badan Penerbit Universitas Diponegoro.

Golnaz, R., Zainalabidin, M., Mad Nasir, S., \& Eddie Chiew. (2010). Non-Muslims' awareness of halal principles and related 
food products in Malaysia. International Food Research Journal, 17, 667-670.

Ghozali., Imam., \& Hengky Latan. (2012). Partial Least Square "Konsep Teknik dan Aplikasi” SmartPLS 2.0 M3, Semarang: Badan Penerbit Universitas Diponegoro.

Greenslade, J. H., McKimmie, B.M., Smith, J.R., Terry, D.J., \& White, K.M. (2009). Social influence in the theory of planned behavior: the role of descriptive, injunctive, and ingroup norms. British Journal of Social Psychology, 48 (1), 135158.

Herlina, S. (2009). Pengaruh Sikap, Norma Subyektif, Dan Kontrol Keperilakuan Terhadap Niat Membeli Handphone Merek Nokia. 3, 38-59.

Hasan,, \& Ali. (2016). Marketing, Jakarta: Medpress.

Hair, J. F., Ringle, C. M., \& Sarstedt, M. (2011). PLS-SEM: indeed a silver bullet. Journal of Marketing Theory and Practice, 19 (2), 139-151.

Hair, J. F., et. al. (2010). Multivariate data analysis, 7, New Jersey: Pearson Education Inc.

Haque, A., Sarwar, A., Yasmin, F., Tarofder, A.K., \& Hossain, M.A. (2015). "Non-Muslim consumers" perception toward purchasing halal food products in Malaysia. Journal of Islamic Marketing, 6 (1), 133-147.

Han, H., \& Ryu, K. (2012). The theory of repurchase decision-making (TRD): Identifying the critical factors in the postpurchase decision-making process. Int. J. Hosp. Manage, 31, 786-797.

Hyun, Joo Lee., \& Zee, Sun Yun. (2015). Consumer's perceptions of organic food attributes and cognitive and affective attitudes as determinants of their purchase intentions toward organic food. Food Quality and Preference, 39, 259-267.
Jamal, A., \& Sharifuddin, J. (2015). Perceived value and perceived usefulness of halal labeling: The role of religion and culture. J. Bus. Res, 68, 933-941.

Jimenez Parra, B., Rubio, S., \& Molina, M.A.V. (2014). Key drivers in the behavior of potential consumers of remanufactured products: A study on laptops in Spain. J Cleaner Prod, 85, 488496.

Jaafar, S.N., Lalp, P.E., \& Mohammed, M. (2012). Consumers Perceptions, Attitudes, and Purchase Intention towards Private Label Food Products in Malaysia. Asian Journal of Business and Management Sciences, 2 (8), 73-90.

Kazmi, A., \& Mehmood, Q.S. (2016). The effect of electronic word of mouth communication and brand image on purchase intentions: A case of consumer electronics in Haripur. Management Science Letters, 6, 499-508.

Kotler., Philip., \& Gary Armstrong. (2012). Principles of Marketing. New Jersey: Pearson Education Inc.

Kotler., Philip., \& Kelvin Lane Keller. (2009). Manajemen Pemasaran, 1, Jakarta: Erlangga.

Kotler, P.A. (2012). Prinsip-Prinsip Pemasaran, Jakarta: Erlangga.

Kotler., Philip., \& Kevin Lane Keller. (2012). Marketing Management, 14, United Stated of America: Pearson Education.

Kim, E., Ham, S., Yang, I.S., \& Choi, J.G. (2013). The roles of attitude, subjective norm and perceived behavioral control in the formation of consumer's behavioral intentions to read menu labels in the restaurant industry. Intl. J. Hospitality Manage, 35, 203-213.

Khan, A., \& Azam, M.K. (2016). Factors affecting halal product purchase intention in India: preliminary investigation. The 
IUP Journal of Marketing Management, 15, (1).

Kuang Chi, H., Huery, R.Y., \& Ya, Ting, Y. (2009). The impact of Brand Awareness on Consumer Purchase Intention: The Mediating Effect of Perceived Quality and Brand Loyalty. The Journal of International Management Studies, 4 (1), 135-144.

Liang, A. R.D., \& Lim, W.M. (2011). Exploring the online buying behavior of speciality food shoppers. Intl. J. Hospitality Manage, 30, 855-865.

Lada, S., Tanakinjal, G., \& Amin, H. (2009). "Predicting intention to choose halal products using theory of reasoned action. Int. J. Islam. Middle East. Finance. Manage, 2 (1), 66-76.

Macchia, S.L., Louis, W.R., Saeri, K.A., Smith, J.R., \& Ogilvie, C. (2013). Predicting facebook users online privacy protection: risk, trust, norm focus theory, and theory of planned behavior.

Moerdiyanto. (2010). Pengertian Kinerja Perusahaan Menurut Para Ahli.

Martins, C.G., Berhens, J.H., Montes Villanueva, N.D., Franco, B.D.G.M., \& Landgraf, M. (2012). Acceptance and purchase intention of irradiated foods in Brazil: Effect of positive information. CENTRUM Catolica's Working Paper Series.

Marwanto., \& Aris. (2015). Marketing sukses, Yogyakarta: Kobis.

Munir, M. (2012). Pengaruh Sikap Konsumen Dan Norma Subyektif Terhadap Minat Beli Produk Sepeda Motor Yamaha "Scorpio" Di Surabaya. Jurnal Cendekia, 1 .

Mas'ud., \& Muchlis, H. (2012). Pengaruh Sikap, Norma-Norma Subyektif dan Kontrol Perilaku Yang Dipersepsikan Nasabah Bank Terhadap Keinginan Untuk Menggunakan Automatic Teller Machine (Atm) Bank Bca di Kota Malang.
Mustari. (2014). Nilai Karakter Refleksi Untuk Pendidikan. Yogyakarta: Raja Grafindo Persada.

Mukhtar, A., \& Mohsin Butt, M. (2012). Intention to choose halal products: the role of religiosity. Journal of Islamic Marketing, 3 (2), 108-120.

Notoatmodjo, S. (2010). Metode Penelitian Kesehatan. Jakarta: Rineka Cipta.

Norazah, M. S., \& Abang Sulaiman, A.S. (2016). Does Halal Image Strengthen Consumer Intention to Patronize Halal Stores? Some Insights from Malaysia. Journal of Islamic Marketing, 7 (1), 120132.

Ozguven, N. (2012). Organic foods motivation factors for consumers. Procedia-Social and Behavioural Sciences, 62, 661-665.

Oentoro, D. (2012). Manajemen Pemasaran Modern. Yogyakarta: Laksbang Pressindo.

Pelau, C. (2011). Analysis of consumer behavior for different product groups. Management \& Marketing, 6, 101-114.

Peter, P., \& Olson, J.C. (2010). Consumer Behavior and Marketing Strategy. McGraw-Hill. New York: ISBN-13: $9780071267816,554$.

Pool, J.K., Najafabadi, A.H.J. (2015). Developing a model to analyze the effects of brand constructs on word of mouth and purchase intention for halal brands. Journal of Global Business Advancement, $8(3), 342$.

Quah, S.H., \& Tan, A.K. (2009). Consumer purchase decisions of organic food products: An ethnic analysis. Journal of International Consumer Marketing, 22 (1), 45-58.

Rehman, A., \& Shahbaz Shabbir, M. (2010). The relationship between religiosity and new product adoption. 
Journal of Islamic Marketing. 1 (1), 6369.

Scalco, A., Noventa, S., Sartori, R., \& Ceschi, A. (2017). Predicting organic food consumption: A meta-analytic structual equation model based on the theory of planned behavior. Appetite, 112, 235-248.

Shah Alam, S., \& Mohamed Sayuti, N. (2011). Applying the theory of planned behavior (TPB) in halal food purchasing. International Journal of Commerce and Management, 21 (1), 8-20.

Shah Alam, S., Mohd, R. \& Hisham, B. (2011). "is religiosity an important determinant on Muslim consumer behaviour in Malaysia?". Journal of Islamic Marketing, 2 (1), 83-96.

Souiden, N., \& Rani, M. (2015). Article information: Consumer attitudes and purchase intentions toward the Islamic banks: the influence of religiosity. International Journal of Bank Marketing, 33 (2), 143.

Shukor, S. A., \& Jamal, A. (2013). Developing Scales for Measuring Religiosity in the Context of Consumer Research.

Son, H., Park, Y., Kim, C., \& Chou, J.S. (2012). Toward an understanding of construction professional's acceptance of mobile computing devices in South Korea: an extension of the technology acceptance model. Autom. Constr, 28, 8290.

Sekaran, Uma., \& Rouger, Bougie. (2013). Research Methods for Business. 4 (2), Jakarta: Wiley.

Triwiyanto. (2014). Pengantar Pendidikan. Yogyakarta: Bumi Aksara.
Vahdati, H., \& Nejad, S. M. (2016). Brand personality toward customer purchase intention: the intermediate role of electronic word of mouth and brand equity. Asian Academy of Management Journal, 21 (2), 1-26.

Ya-Hui, Wang., \& Cing-Fen, Tsai. (2014). The relationship Between Brand Image and Purchase Intentions: Evidence from Awards Winning Mutual Funds. The International Journal of Business and Finance Research, 8 (2), 27-40.

Wilson, J.A.J., \& Liu, J. (2011). The challenges of Islamic branding: navigating emotions and halal. Journal of Islamic Marketing, 2 (1), 28-42.

Yang, K., \& Jolly, L.D. (2009). "The effects of consumer perceived value and subjective norm on mobile data service adaption between American and Korean consumers", Journal of Retailing and Consumer Services, 16 (6), 502-508.

Yesenia., \& Siregar, E. H. (2014). Pengaruh Kualitas Layanan dan Produk terhadap Kepuasan serta Loyalitas Pelanggan KFC di Tangerang Selatan. Jurnal Manajemen dan Organisasi, 5 (3).

Zeeshan, Z. (2013). The impact of mobile service attributes on males' and females' purchase decision. Management \& Marketing Challenges for the Knowledge Society, 8 (4), 669-682.

Zhou, X., Lynch, Jr, J.G., \& Chen Q. (2010). Reconsidering Baron and Kenny: Myths and Truths about Mediation Analysis. Journal of Consumer Research. 37, 197-206. 